\title{
REFLEX DISTURBANCES IN THE CAUSATION
}

\section{OF EPILEPSY.'}

BY IVILLIAM C. KRAL'SS, M.D.,

Buffalo, N. Y.

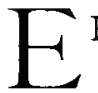

PILEPSY must be considered as a complex symptom arising from a multiplicity of causes. That form of epilepsy due to peripheral irritation becomes every day more and more realistic to me, so that I am fast becoming a skeptic on the question of idiopathic spontaneous epilepsy.

The tendency of the times is to find a cause for every effect, and to regard with suspicion every effect that has no appreciable cause. If, after an unsuccessful attempt to find some provocative agent, and the epilepsy dates from infancy, coupled with an inherited neurotic temperament, then I am satisfied with the term idiopathic. This designation, however, signifies but little except perhaps to believers in spontaneous generation; it does not imply that some cause may or may not have been present-only that we are unable to find it, and so puts a scientific varnish on an otherwise faulty and unpolished conclusion.

We learn by studying the fundamental laws of nature that all matter is in a constant state of motion, and anything that hastens or retards this vibration produces an equivalent amount of heat or heat values. Moreover, that force cannot be annihilated. If destroyed in one form it reappears in another, without suffering any loss. Apply these laws to the human system and we can account for reflex epilepsy perhaps as follows: A perfectly normal nervous system holds sway over a healthy, vigorous organism; the functions of secretion, excretion

${ }^{1}$ Read at the 87 th annual meeting of the Medical Society of the State of New York, held at Albany, N. Y., Feb. 7-9, I893. 
and assimilation follow closely the physiological laws governing them. The result of these metabolic forces means work, either mental, or physical, or both along some clearly defined channel. The whole system, then, is in a normal state of motion, each fiber and gland working faithfully and assiduously to keep the structure in a state of perfect equilibrium. Perchance a nerve trunk or nerve terminal is subjected to some insult causing obstruction, retardation or interference of its molecular vibration; accordingly, heat units or heat values are generated because of this irritation, reflected to the great heat centre, the brain, and these converted into heat equivalents such as pain, tremor, spasm, etc., referable to the seat of the initial lesion. This process continuing indefinitely without relaxation, accumulation of heat values ensues and an explosion of nerve force is the result.

Reflex epilepsy means, therefore, a state of irritation of the cerebral centres produced not by a central but by a peripheral lesion. The peripheral irritation is reflected to its cerebral center in the same manner that a central or cerebral lesion reflects the irritation to the extremities. Thus in Jacksonian, epilepsy a lesion pressing upon the motor center of the right arm is manifested by spasms beginning in that arm; and likewise, in general epilepsy, the point of origin of the aura denotes most probably the seat of irritation in the cortical centers of the brain.

The line of demarcation between reflex and traumatic epilepsy should be sharply drawn. In the latter the irritative lesion is direct and local, the result of a trauma to the cranium, and the consequent convulsions are in a degree amenable to the surgeon's art, still not to such an extent as was claimed by observers a few years ago. This form of epilepsy will receive worthy attention in a subsequent paper.

It is true that not every scar, ingrown toenail, phimosis, pinworm, or what not, begets reflex cerebral disturbance, or else this form of disease would be as wide spread and prevalent as was the itch during the middle ages. Therefore some other property or idiosyncracy 
must be present in order that the conditions be fulfilled. A neuropathic disposition, either inherited or acquired, is the sina quâ non of this symptom-complex. This need not necessarily be present at the time the irritation commences, but may be saddled upon the system, the result of the tireless, unceasing effort of the brain to counteract the nerve strain. The patient in a short time becomes peevish, excitable, anæmic, and the parents will state that the child has of late "become nervous." In those cases of an inherited neurotic disposition, the convulsive attacks appear much sooner after the advent of the irritative lesion, and as a rule the epileptic habit is early and fast ingrafted upon the constitution. This irritation once relieved or remedied, the habit still persists in these latter cases, and to all intents and purposes the patient has the appearance of suffering with idiopathic epilepsy. When such is the case, the nature and origin of the disease is almost impossible to ascertain, and the epilepsy is erroneously classified as spontaneous or inherited.

The question may now be asked, what shall we look for in deciding the immediate causation of reflex epilepsy? As a rule, "whenever practicable, I have the patient remove all his clothing and examine him thoroughly, beginning with the feet.

Ingrown toenails, corns and callouses are not infrequently the cause of epilepsy. Scars about the limbs, disorders of the genitalia, incomplete descent of one or both testes are some of the causes in youth. In girls the condition of the clitoris and mouth of the vagina should be carefully ascertained; also whether there is incontinence of urine or the presence of oxyurides in the vagina or rectum. Hare, in his monograph on epilepsy, says "that it may be laid down as a fact that in all cases in girls, in which epilepsy of unknown cause develops, the vagina should be examined for the presence of any pin worms which may have emigrated from the rectum." The condition of the rectum should not be overlooked, but carefully explored for ulcers and irritating hemorrhoids. Coming to the head we have an extensive field for ex- 
amination. The mouth, nose, ears, eyes and scalp may all harbor seemingly trivial disturbances, which under other circumstanceswould pass unheeded and unnoticed. Disorders of dentition, such as faulty direction in the growth of the teeth, hidden fangs, caries, neoplasms in and about the buccal cavity, retained foreign bodies in the pharynx, scars, the result of ulcerative or specific processes about the tonsils, tongue and larynx, polypi and foreign bodies in the nose and ears, disorders of refraction; in short, whatever can impinge either directly or indirectly upon nerve trunks or nerve filaments, other conditions being equal, may produce reflex symptomatic epilepsy. 'These, then, are some of the external causes, and to discover them is easy, very easy, as compared with the probable internal causes. No doubt you are all acquainted with the stomach as a very frequent contributor to this subject. Those of us who pay special attention to nerve diseases receive many cases labelled epilepsy due to stomach trouble. The round worms of the intestine are a common cause, and have been recognized as one of the most prolific agents in the etiology of this disease. Disturbances of nearly every internal organ have, according to various writers on this subject, at one time or another produced epilepsy.

There are two organs, however, in this list of causative agents, to which I briefly invite your special attention-namely, the stomach and the urethra-two of the most important canals known to man, lay or professional. The stomach, because it receives not only that which nourishes and sustains the human economy, but nearly everything else that cannot be conveniently sewered in some other way; the urethra, because through it flow little drops of water mixed with little grains of sand, and at times another fluid coming from another gland. In a boy, and not necessarily such a small boy, either, what two organs are subject to more use-abuse-and refuse - and what two organs call forth more care-repair-and despair? Surely none. The importance of the stomach as a primary etiological factor in the causation of reflex 
epilepsy is, in myopinion, overestimated. I will not deny that the indigestion of indigestable matter invites convulsions, and that after a brisk purge or emesis they disappear. Many patients tell their physician that such was the cause, the starting point of the first attack, and the physician confidingly tells the specialist the same story. 'They will further testify that they can foretell the approach of an attack by the voracious appetite, peculiar sensation at the pit of the stomach, vomiting of watery fluid, and the patient's desire to eat anytling and curything that comes within his reach. Put this patient on a. bland or exclusive milk diet and keep him on it for months; give him pepsin, trypsin, papoid, etc., and if your experience is similar to mine, he will continue to convulse and froth at the mouth, and you are fortunate indeed if his parents do not become similarly affected. I believe that in many of these cases we are on the wrong trail and must seek the cause elsewhere. The symptoms denoting gastric affinity are not so much epileptogenic as epileptopathic. These disturbances, as the patient and parents declare, hold a close relation to the paroxysms, and I believe they are only localized epileptic attacks or epileptic equivalents. The increased tension in which the nervous system is held just prior to an attack, stimulates the gastric glandular system, through the sympathetic and pneumogastric nerves calling forth an abnormal secretion of gastric fluids, and the flow of gastric juice means an appetite. The stomach naturally becomes tender and hyperasthetic under such rule long continued, and anything that irritates or demands undue attention is rewarded with stern rebuke. I have seen the stomach perform similar antics in hysteria and general paresis, and yet neither you nor I would affirm that the gastric trouble was the cause of these ailments.

Now turn to the urethra, such as is controlled by a boy from his eighth to eighteenth year. He may live high or live low, be a street urchin or mother's pride, a country lad or a city tough, it matters little, he is for all that a boy-and as dogs will be dogs so boys will be boys. 
The same old story-he has eaten green apples and has had fits. He has been doctored for his stomach, and strangely enough the fits still persist. As he comes into your office you notice that his head hangs, his eyes are dull and sunken, his gait labored and heavy and his answers are backward and evasive. You put the question direct and with some force, and he admits that he has occasionally masturbated, but that he learnt it from the other boys. Now, instead of upbraiding and threatening him you do your duty, and examine his genital organs inside as well as outside, and in nine cases ont of ten you will find some irritation seated most generally in connection with the penis. The prepuce may be too long or too short, adherent or constricted; the frenulum too short, producing a mild form of hyporpadias; or the prepuce has never been everted, and large accumulations of smegma are present. Supposing that none of these conditions are found, you have still the most important examination to make-the exploration of the urethra-and how often is it undertaken in these cases. The boy has never had connection, and hence you infer no gonorrhcea with its attending inflammation and strictures. But try to pass a No. 12 or 15 Benas catheter; and, although they glide along so nicely at other times, you are beset with obstacles in passing through constrictions, evading the boy's hands, and in convincing him that his urethra is anæsthetic and he cannot have any pain. I am thoroughly satisfied that there are many disturbances present in a good boy's urethra which prompt him to vicious habits; and they, in turn, if his constitution is impressionable, lead to serious nervous disorders, such as chorea, epilepsy, neurasthenia, etc. Vegetations, polypi, cysts or other neoplasms in the walls of the urethra, producing constrictions, hyperæsthetic areas, slow forms of inflammation are translated by such symptoms as priapism, spasm of the urethral muscles, frequent micturition, spermatorrhoea, masturbation, and sexual excesses. The influence of these morbific agencies upon the nervous system is too well known to be here reriewed. In a 
short period of time I have treated six boys with reflex neuroses, five of whom had refiex epilepsy due to disturbances along the urethral canal. In some of these cases I have found the meatus urinarius surrounded by a red border or ring, portraying perhaps the congestive state of the urethral lining. An urethroscopic examination should never be omitted, for by its revelation the exact nature of the lesion can be determined.

My treatment of these cases has been, besides the administration of bromides, in the use of a mild galvanic current of from one to five miliamperes, each treatment lasting about three minutes, three times weekly. In the employment of the ordinary urethral electrode I have been annoyed by several inconveniences. The common olive point electrode is more or less inflexible; besides, having a metallic point, its introduction in many cases becomes difficult, owing to the fact that a contraction of the walls of the urethra is produced by the stimulus imparted to the mucous membrane by the metal. Then, too, in cases of stricture, vegetations, etc., where the electrolytic action is desired, the metallic point is liable to produce injury in its passage; or when the olive is in close proximity to the sphincter vesicæ, a strong current may cause unpleasant sequellæ.

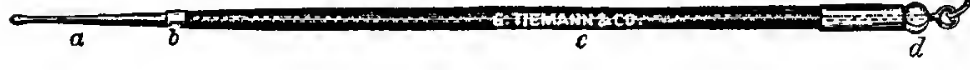

To overcome these drawbacks Messrs. Geo. Tiemann $\&$ Co., of New York, have made, at my instigation, an electrode possessing lightness, flexibility and a non-metallic bulbous point." A Benas catheter, $c$, or bougie,is encircled by a narrow steel band, $b$, about $\mathrm{I}$ to $\mathrm{I} \frac{1}{2}$ inches from its bul. bous extremity, $a$. This band is connected with the attach. ment, $d$, by means of a soft copper wire extending through the interior of the catheter. The electrode is made in two sizes, No. 15 and No. 20 of the French scale.

In all cases in which it has been employed thus far it has given perfect satisfaction.

'See The Journal of Electro-Therapeulics, Vol. X, No. 4. 
In conclusion, I wish to report a case which to me is a typical one of reflex epilepsy :

Bessie B.: Astr, 3 years, Io months; actight, 3 I pounds; hight, 37 inches; constitution, rather delicate; complixion, fair: hair, brown; iycs, blue.

Antecclents.-Parents both living and healthy, offering no hereditary taint of any kind; no history of syphilis or tuberculosis.

Early History.-Born at full term. Dentition passed off smoothly, with the exception of some slight gastric trouble which lasted but a few days; had no convulsions of any kind. She learnt to walk in her tenth month. When two years old she was troubled with ascarides, diagnosed by their presence in the feces, condition of the child and reflex phenomena. She did not, however, at any time fall into convulsions.

At three years she passed through a severe attack of whooping congh. Otherwise the child passed its early infancy without any serious disturbance; seemed to be in perfect health, never complaining, always bright, active and cheerful.

Status Proscns.- Rather anæmic, but well dereloped child, offering no particular stigmates except the one to be described later on. Sensation, mobility and organs of sense unimpaired; organs of secretion and excretion in grood working order; no glandular enlargements, and percussion of head is not sensitive. Of late she has become uneasy, restless, touchy, or, as the mother aptly terms her condition, "she has become nervous."

On March 8 th, I 888 , as the mother was scrubbing the floor, the child, unnoticed, entered the room, stumbled and fell sideways into the tub of boiling water. The outer side of the left leg from the hip to the foot was badly burned and blistered. She was put in bed, suffered great pain for two weeks, then made a rapid recovery. At first she was timid about walking, and limped about for some weeks, complaining of pain at the left knee-joint. An examination of the left leg rerealed a cicatrix nearly quadrilateral in shape, situated at the bend of the knee. With the leg extended it measured 5 centimeters in length, and varies from 4-5 centimeters in width. Situated on the outer side of the leg between the outer edge of the patella and the tendon of the biccps muscles. Free movement of the knee-joint is not inter- 
fered with. The cicatrix is non-adherent, tender and painful, of a pinkish color, and presents one nodosity cordlike in appearance.

In May, is88, the mother noticed that at times, while the child was walking, she would suddenly stop, the left leg would stiffen, and the toes, acting as a fulcrum, the whole member would rotate outwards, the child's expression would change, but it remained conscions,complaining of a pain seeming to radiate from the vicinity of the kneejoint. The attacks lasted from I to 2 minutes. No other phenomena were noticed, and the mother thought the trouble was caused by a faulty shoe.

These attacks occurred at first once daily, sometimes twice, continually growing more severe until both extremities became affected. About November, I888, the child would awaken at night, generally soon after retiring, cry out, the legs would stiffen, then would kick violently for a few moments. The arms remained motionless; no incontinence of urine, no frothing at the mouth: and no loss of consciousness. These attacks lasted from 3 to 5 minutes, the mother thinks, and would occur nightly for sometime, then cease for one to two weeks. Soon these spasms became general. The arms as well as the legs would be seized with tonic, then clonic contractions, followed by loss of consciousness, incontinence of urine, frothing and bleeding at the month, pathognomonic symptoms of classical epilepsy. This condition of things existed at the time that I first saw the child in September, I 889 .

I made a diagnosis of epilepsy of reflex character and laid out the following treatment: The cicatrix being too large for excision, I advised painting it daily with collodion. Internally, I prescribed equal parts of the Bromides of sodaammonia and potassium, 5 grains three times daily, and the administration of cod-liver oil. On this treatment the child reacted nobly and the attacks became less severe and less frequent. After two months' treatment the cicatrix appeared more healthy and not painful to pressure. At the end of six months the attacks had disappeared and since then there has been no recurrence. The bromides were gradually dispensed with, and at the present time the parents consider the child cured. 